\title{
Hemizygosity for Atm and Brca1 influence the balance between cell transformation and apoptosis
}

\author{
Fengtao Su', Lubomir B Smilenov²*, Thomas Ludwig ${ }^{3}$, Libin Zhou', Jiayun Zhu', Guangming Zhou', Eric J Hall ${ }^{2}$
}

\begin{abstract}
Background: In recent years data from both mouse models and human tumors suggest that loss of one allele of genes involved in DNA repair pathways may play a central role in genomic instability and carcinogenesis. Additionally several examples in mouse models confirmed that loss of one allele of two functionally related genes may have an additive effect on tumor development. To understand some of the mechanisms involved, we examined the role of monoallelic loss or Atm and Brca1 on cell transformation and apoptosis induced by radiation.

Methods: Cell transformation and apoptosis were measured in mouse embryo fibroblasts (MEF) and thymocytes respectively. Combinations of wild type and hemizygous genotypes for ATM and BRCA1 were tested in various comparisons.

Results: Haploinsufficiency of either ATM or BRCA1 resulted in an increase in the incidence of radiation-induced transformation of MEF and a corresponding decrease in the proportion of thymocytes dying an apoptotic death, compared with cells from wild-type animals. Combined haploinsufficiency for both genes resulted in an even larger effect on apoptosis.

Conclusions: Under stress, the efficiency and capacity for DNA repair mediated by the ATM/BRCA1 cell signalling network depends on the expression levels of both proteins.
\end{abstract}

\section{Background}

In recent years data from both mouse models and human tumors, suggest that loss of one allele of genes involved in DNA repair pathways may play an important role in carcinogenesis. Haploinsufficiency as a result of loss of allele for APC, ARF, ATM, BRCA1, BRCA2, LKB1, CDKN1B, P53, RB and other proteins has been shown to contribute to tumorigenesis [1-6]. Additionally, several examples in mouse models confirmed that hemizygosity for functionally related genes may have an additive effect on tumor development. Combined hemizygosity for Xpc and p53, Atm and p53, and Fen 1 and $A p c$ genes predispose humans to UV radiation-induced skin cancer, mammary carcinoma or adenocarcinomas, respectively [7-9]. Importantly, hemizygous genotypes did not contribute to tumor development alone, but if

\footnotetext{
* Correspondence: lbs5@columbia.edu

${ }^{2}$ Center for Radiological Research, Columbia University Medical Center, New
} York, NY 10032, USA combined with hemizygosity for another gene involved in DNA repair, the contribution became significant. All of this evidence suggested that tumorigenesis may depend on the expression levels of single or combination of proteins. We have reported that primary mouse cells haploinsufficient for either of two important DNA repair proteins, Atm or $\operatorname{Rad} 9$, are more sensitive to transformation by radiation and are less apoptotic when compared with wild-type controls [10]. Furthermore, cells doubly haploinsufficient for Atm and Rad9 showed an even higher level of radiation-induced transformation and an even lower level of apoptosis than those cells haploinsufficient for either one of these proteins alone. We now extend these studies to primary mouse cells derived from animals hemizygous for Brcal and Atm. Earlier reports suggested a link between Atm heterozygosity and breast cancer. The reported estimated relative risk varied in the range of 1.5 to 12 fold [11-13]. Different mechanisms by which ATM heterozygosity contributes to breast cancer pathobiology were proposed,

(2) 
most of which were associated with the expression of dominant negative ATM protein $[14,15]$. However a large number of the detected ATM mutations in familial breast cancer cases are actually result in truncated gene products resulting in no expression of ATM protein from the mutant allele [13]. The frequency of such mutations is also very high (> 80\%) in ATM patients $[16,17]$. Importantly, the frequency of $A T M$ heterozygotes with null mutation for one of the alleles could be as high as $1-3 \%$ of the US population $[18,19]$. Taken together, these observations led us to investigate the effects of monoallelic loss for two genes - ATM and BRCA1 in primary cells for two endpoints: cell transformation and cell apoptosis. Cells matching these criteria were derived from established Atm and Brca1 heterozygous parental strains of mice. In both parental strains, one of the alleles of the Atm or Brcal genes was truncated, resulting in loss of expression of the corresponding protein from the truncated allele. The biological function and roles of ATM and BRCA1 are relatively well established. Both proteins are involved in DNA repair and function as sensor/transducers. ATM is involved in the earliest events in DNA double strand break detection and initiates the activation of several pathways linked to cell cycle checkpoint controls [20]. ATM also recruits DNA repair proteins to sites of DNA damage and, along with BRCA1 is part of supramolecular DNA repair complex comprised of many factors [21]. The phosphorylation of BRCA1 by ATM is an important event in the activation of the S/G2 and G2/M checkpoints [22]. BRCA1 likely plays multiple roles in the mechanisms of physical repair of DNA [23,24]. Mutations of either protein are associated with tumor development. ATM deficiency results in lymphoid malignancies and BRCA1 mutation carriers have 50-85\% life risk of developing breast cancer [25]. We hypothesize that the appropriate function of signaling networks that facilitate either DNA damage repair, cell signaling, or programmed cell death, depends on the expression levels of key proteins. Consequently, hemizygosity causing haploinsufficiency may create conditions where network efficiency is reduced leading to decreased effectiveness of DNA repair. In this study we show that hemizygosity for either Atm or Brcal or both increases the incidence of cell transformation and decreases apoptosis. Remarkably, cells hemizygous for both genes show the lowest levels of radiation-induced apoptosis.

\section{Methods}

Mice

Atm and Brcal heterozygous (+/-) animals have been described previously [26,27]. In both mouse models one of the Atm or Brcal alleles have been disrupted by targeted mutagenesis. This mutagenesis prevented any protein synthesis from the targeted alleles. As a result, Atm or BRCA1 proteins were coded only from the wild type alleles. Atm and Brcal hemizygous mice were mated and only F1 littermates were used. Genotypes were determined by PCR. The p53 status was "wild type" for both genotypes as shown earlier $[27,28]$

\section{Embryo Cell Preparation}

Pregnant mice were sacrificed on day 14 of the gestation. Mouse embryo fibroblasts (MEF) from each embryo were cultured separately with DMEM high glucose (Invitrogen) supplemented with 15\% FBS (ATCC) and then genotyped. Four genotypes of MEF cells from the same litter were used for each experiment: wildtype, (Atmwt/Brcalwt), single hemizygous (hz) for Atm (Atmhz/Brca1wt) single hemizygous for Brcal (Atmwt/ Brcalhz) and double hemizygous (Atmhz/Brcalhz).

\section{Cell Transformation Assay}

Exponentially growing MEFs received a dose of 2 Gy of $\gamma$-rays in an acute exposure, and controls were shamirradiated. MEFs were then plated in $10 \mathrm{~cm}$ plates at a density of 6,000 cells/plate over a feeder layer of 70,000 cells prepared from the same embryo but irradiated previously with a supralethal dose of $30 \mathrm{~Gy}$. After 2 weeks of growth in DMEM medium supplemented with $10 \%$ fetal bovine serum at $37^{\circ} \mathrm{C}$ in a $5 \% \mathrm{CO}_{2}$ air-humidified incubator, cells were fixed, stained, and yields of transformed clones scored. The scoring criteria was developed and examined by preliminary experiments, where embryo cells were irradiated and plated at the same density. The clones which seemed dense and had stellate-shaped piled cells were photographed and isolated with cloning cylinders. These clones were expanded and injected into nude mice. Those that caused the development of subcutaneous tumors were designated as transformed. Clones that matched their shape and dimensions were scored as transformed in later experiments. Plating efficiency, cell surviving fractions, and the spontaneous and radiation-induced frequency of transformation were determined.

\section{Evaluation of micronuclei}

Exponentially growing MEF cells were plated at density of 50,000 cells/well of 12-well plate. Next day, the cells were exposed to various doses of $\gamma$-rays. Immediately after irradiation, $1.5 \mu \mathrm{g} / \mathrm{ml}$ of cytochalasin B (Sigma) was added to each well. 24 hours later, the cells were fixed with acetic acid and methanol $(\mathrm{v} / \mathrm{v}=3: 1)$, and stained with $3 \mu \mathrm{g} / \mathrm{ml}$ of acridine orange (Sigma) for 1 $\mathrm{min}$. Micronuclei in binucleated cells (BN) were counted under fluorescent microscope. More than $500 \mathrm{BN}$ cells were scored for each sample. 


\section{Apoptosis assay}

Mice were irradiated with 5 Gy of $\gamma$-rays. 24 hours later, thymuses from the irradiated and sham-irradiated control mice were isolated, weighed and homogenized gently for single cell suspension preparation. After estimation of the total cell number, $1 \times 10^{6}$ cells from each genotype were labeled with $\mathrm{CD}^{4+}$ and $\mathrm{CD}^{8+}$ specific antibodies (Pharmingen) and two color flow cytometry analysis was used to estimate the survival of each thymocyte subtype. Total of 20,000 cells for each genotype were examined and the percent of double positive $C D^{4}$ ${ }^{+} / \mathrm{CD}^{8+}$ cells was estimated based on that number.

\section{Comet Assay}

DNA damage and repair were evaluated with alkaline comet assay according to the report by Olive et al [29] with some modifications. Single MEF cells were harvested by trypsin treatment and resuspended in DMEM containing $10 \%$ FBS at a concentration of $1 \times 10^{6}$ cells/ $\mathrm{ml}$. An aliquot of $100 \mu \mathrm{l}$ cell suspension was mixed with $300 \mu \mathrm{l} 0.5 \%$ low melting-point agarose (Amresco) in DMEM containing 10\% FBS. $100 \mu \mathrm{l}$ of the mixture was layered on glass slide pre-coated with $0.5 \%$ LE agarose and covered with another glass slide. After brief incubation on ice for agarose solidification, the cover slides were carefully removed and the samples were gently immersed into freshly prepared lysis solution $(2.5 \mathrm{M}$ $\mathrm{NaCl}, 10 \mathrm{mM}$ Tris, $1 \%$ sodium lauryl sarcosinate, 100 mM EDTA, 1\% Triton-100, and 10\% DMSO) for $1.5 \mathrm{hrs}$ followed by incubation for $20 \mathrm{~min}$ in electrophoresis buffer ( $1 \mathrm{mM}$ EDTA, $300 \mathrm{mM} \mathrm{NaOH}, \mathrm{pH}>13)$. The electrophoresis was performed in the same buffer ( 20 min, $20 \mathrm{~V}, 300 \mathrm{~mA}$ ). The samples were neutralized with $0.4 \mathrm{M}$ Tris- $\mathrm{HCl}$ buffer ( $\mathrm{pH}$ 7.5) and air-dried after a brief fixation with $70 \%$ ethanol.

Individual cells were visualized with BrdU staining and photographed under fluorescence microscope. 100 comets of each sample were analyzed with a free software called Casp [30].

\section{Results}

\section{Cell Transformation Assay}

Radiation-induced transformation of MEF was examined as a surrogate for carcinogenesis in vivo. A total of 19 embryos from five litters were used and included the following genotypes: Atmwt/Brcalwt, Atmwt/Brcalhz, Atmhz/Brcal wt and Atmhz/Brca1hz. Yields of transformed clones were measured both for unexposed controls and after a dose of $2 \mathrm{~Gy}$. The results shown in Tables 1 and 2 indicate a statistically significant increase in transformation frequency for the single and doubly hemizygous cells. Transformation frequencies for these cells were nearly two times higher than the one of wild-type cells. Brca1 hemizygotes show a similar transformation frequency as the Atm hz, however, the interesting point to note is that the double hemizygotes Atm/Brcal, show little or no increase over Brcalhz or Atm hz alone. There were small statistically not significant differences in the clonogenic survival for all populations after irradiation (results not shown).

\section{Background DNA damage estimation in the different genotypes}

In these experiments we accessed the background DNA damage in all four genotypes by alkaline comet assay (Figure 1). Notably there were statistically significant differences in the tail moments between the wild type and all hemizygous genotypes. These differences illustrate that cells that are singly or doubly hemizygous for Atm and Brcal have more background DNA damage than wild type cells. This elevated background of DNA damage may point to the higher vulnerability of these cells to DNA damage and cell transformation if additional damage is induced.

\section{Micronucleus Assay}

Figure 2 shows the data for micronuclei, scored in binucleated cells, 24 hours after exposure to graded doses of 0.5 to 3 Gy of $\gamma$-rays. There was a statistically significant increase of micronuclei in cells hemizygous for both Atm and Brcal at the highest dose, but for lower doses no such differences were found. These results suggests that the DNA damage induced by radiation is less efficiently repaired in double hemizygous cells and may point to an increased mutation accumulation in these cells after DNA damage is induced.

\section{Apoptosis of Thymocytes}

We examined the survival of the most numerous type of cells in the thymus (more than $80 \%$ of all cells), CD4 ${ }^{+} / \mathrm{CD}^{+}$thymocytes, after in vivo $\gamma$-irradiation (Figure 3 ). As expected, $24 \mathrm{hrs}$ after irradiation the numbers of $\mathrm{CD}^{+} / \mathrm{CD}^{+}$cells were significantly reduced. The survival of $\mathrm{CD}^{+} / \mathrm{CD}^{+}$cells from single Atm hemizygous mice was $10 \%$ higher than the wild type controls. Interestingly, the survival of Brca1 hemizygous thymocytes trends similarly. However, compared with the other three genotypes, the survival of the double hemizygous thymocytes was significantly higher. More than $40 \%$ of these thymocytes survived which shows that they are more resistant to radiation and less apoptotic than the other genotypes examined. This implies that Atm/Brca1 cells may accumulate mutations at a higher rate than the other genotypes.

\section{Discussion}

This study demonstrates that cells hemizygous for either Atm or Brca1 are more sensitive to transformation by 
Table 1 Transformation frequencies of unirradiated or irradiated cells differing in the status of Atm and Brca1.

\begin{tabular}{|c|c|c|c|c|}
\hline Genotype & Dose (Gy) & Total number of clones scored & Number of transformed clones & $\begin{array}{c}\text { Transformed } \\
\text { clones (\%) }\end{array}$ \\
\hline \multirow[t]{2}{*}{ Atmwt/Brcalwt } & 0 Gy & 31220 & 7 & 0.02 \\
\hline & 2 Gy & 21880 & 26 & 0.12 \\
\hline \multirow[t]{2}{*}{ Atmwt/Brcalhz } & 0 Gy & 34380 & 11 & 0.03 \\
\hline & 2 Gy & 17142 & 32 & 0.19 \\
\hline \multirow[t]{2}{*}{ Atmhz/Brcalwt } & 0 Gy & 34170 & 11 & 0.03 \\
\hline & 2 Gy & 16720 & 36 & 0.21 \\
\hline \multirow[t]{2}{*}{ Atmhz/Brcalhz } & 0 Gy & 26660 & 9 & 0.04 \\
\hline & 2 Gy & 12046 & 27 & 0.22 \\
\hline
\end{tabular}

radiation and exhibit defective induction of apoptosis under stress. Remarkably, combined hemizygosity for both genes show additive negative effect on apoptosis induction and increased genomic instability reflected by micronuclei formation.

In recent years, epidemiological data as well as studies in mouse models confirmed that heterozygosity may play a significant role in tumor initiation and development. The most striking conclusion from these experiments is that heterozygosity for a single gene may contribute to tumor formation. To what degree this may reflect in increased cancer risk heterozygous carriers is a very important issue which can be resolved only after understanding the mechanisms underlying the role of heterozygosity in tumor formation. The role of heterozygosity is more obvious in cases where the product of the mutant allele is a truncated protein having dominant negative effect. Truncated versions of P53, Rb, Ras, NF1, ATM, BRCA1 and 2, INK4 family of proteins, CREB binding protein (CBP) and others have been identified in different tumors [31,32]. Much more difficult to explain are the instances where the mutant allele does not produce any protein. Cumulative data acquired in cases where the role of heterozygosity of a gene (one allele inactivated, no protein expression from it) was studied in mouse models, show that more than twenty genes could be implicated in tumor development [33]. A subset of these 20 genes is included in the group of

Table 2 Comparisons of radiation induced transformation between MEFs of different genotypes vs. wild type MEFs.

\begin{tabular}{lccc}
\hline & $\begin{array}{c}\text { Atmhz/ } \\
\text { Brca1wt }\end{array}$ & $\begin{array}{c}\text { Atmwt/ } \\
\text { Brca1hz }\end{array}$ & $\begin{array}{c}\text { Atmhz/ } \\
\text { Brca1hz }\end{array}$ \\
\hline $\begin{array}{l}\text { Relative } \\
\text { transformation }\end{array}$ & 1.8 & 1.66 & 1.88 \\
(2 Gy) & & & \\
\hline t-test & $\mathrm{P}=0.03$ & $\mathrm{P}=0.05$ & $\mathrm{P}=0.018$
\end{tabular}

Relative transformation is defined as the ratio of the number of transformed clones per surviving hemizygous cells relative to the number of transformed clones per surviving wild type cells. The statistical significance of differences in transformation frequency between the various cells with hemizygous genotypes and wild type cells was analyzed by the Student's t-test. the 300 known cancer genes [34]. Many of these genes maintained their hemizygous status in the tumors that developed as a result of their hemizygosity. In general, the only difference between the wild type and hemizygous status of these genes was the haploinsufficiency for the corresponding protein.

We hypothesize that haploinsufficiency is a factor mostly in acute cell conditions, where different factors trigger stress response pathways. Due to the networked nature of this response, the insufficient expression level (s) of some proteins may lead to reduced overall

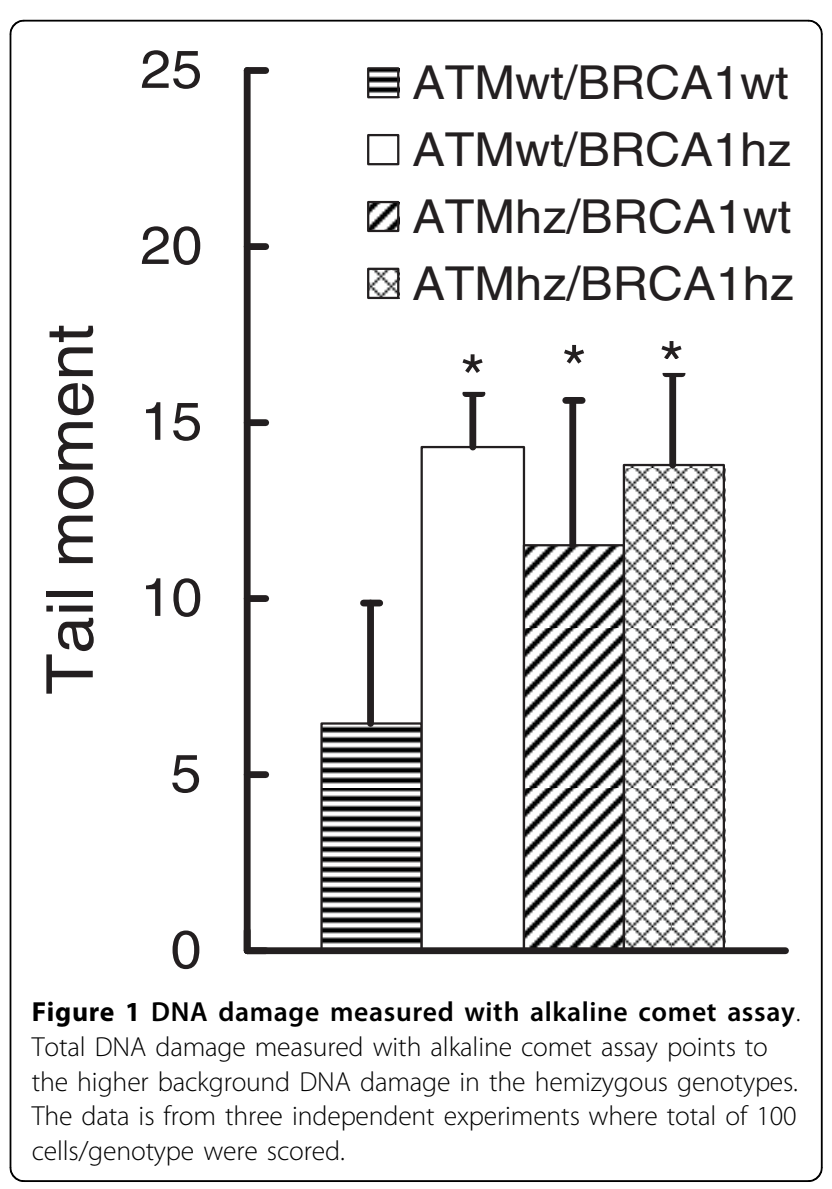




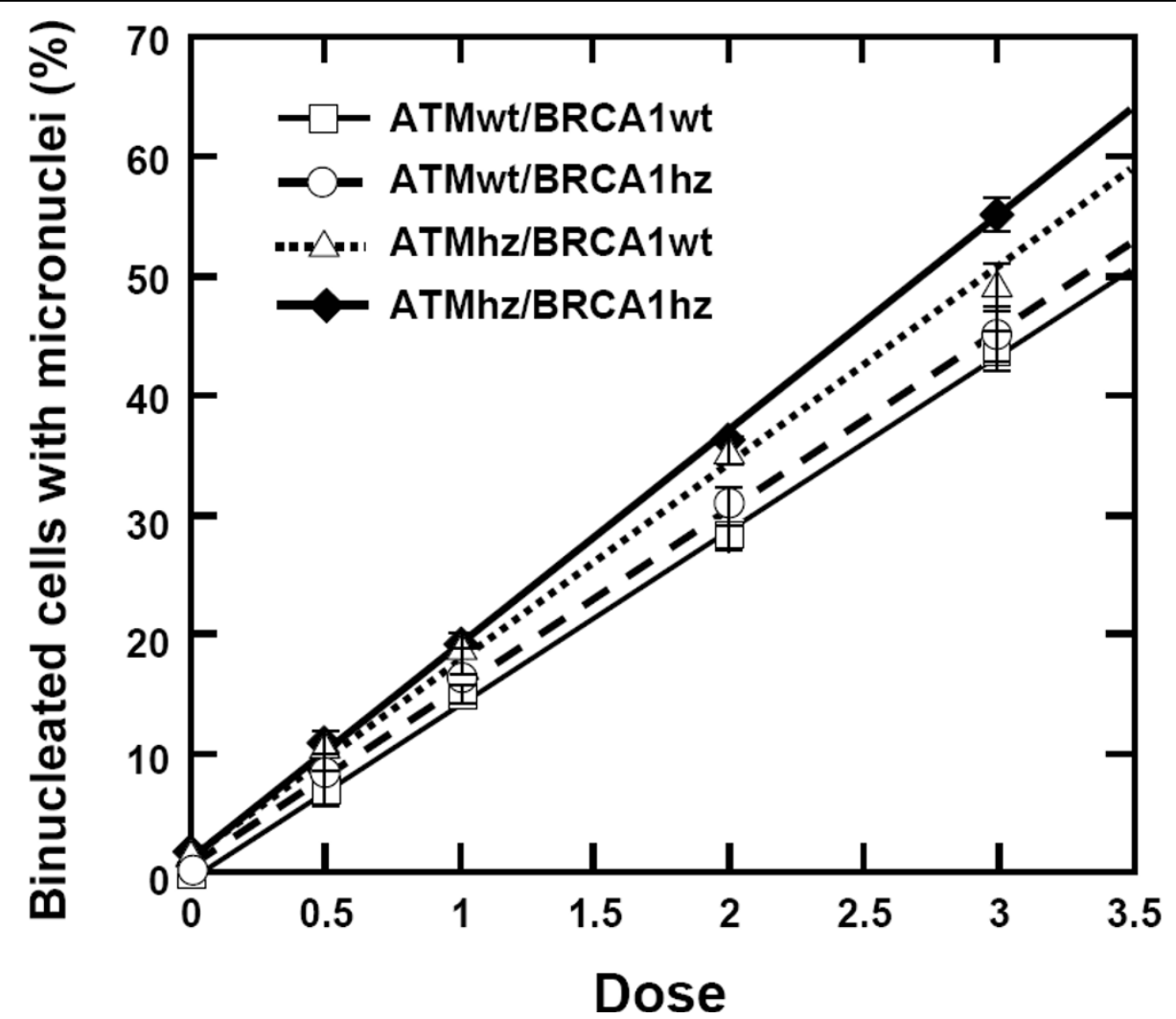

Figure 2 Induction of micronuclei by graded doses of radiation. Induction of micronuclei by graded doses of radiation in mouse embryo fibroblasts having different genetic backgrounds. Data are shown as a mean and standard error from 3 independent experiments. At a dose of 3 Gy of $\gamma$-rays, there is a statistically significant difference between the double hemizygous and the other genotypes.

network response. As a consequence, stress related processes, apoptosis for example, may be less effective. Previously, we substantiated this idea using a system where both Atm and Rad9 genes were haploinsufficient [10]. In the current study we used another pair of DNA repair genes - Atm and Brcal. As was the case in our prior study, the background transformation frequency of MEF was the same for all studied genotypes. Remarkably, the transformation frequency after induced DNA damage was dependant on the genetic background. Both hemizygous genotypes show statistically significant increases in cell transformation in comparison with the wild type cells. Interestingly, the transformation frequency of MEF on a doubly hemizygous background was in the same range as the singly hemizygous MEF which indicated that there is no additive effect of hemizygosity for Atm and Brcal genes for this endpoint. Nevertheless, these results confirm that stress related pathways may depend on proper expression levels of these key proteins.

The induction of genomic instability was monitored by measuring micronuclei $(\mathrm{MN})$ formation. In one set of experiments, we determined the induction of $\mathrm{MN}$ in different genotypes. Our results show that combined hemizygosity for Atm and Brcal genes results in elevated levels of MN. This observation supports the conclusion from the transformation experiments and indicated strongly that processes active under stress depend on the expression levels of both Atm and Brca1 proteins.

The induction of cell transformation is thought to depend on the efficiency of apoptosis induction. In order to estimate the role of genetic background in apoptosis induction, and since ATM plays very important role in thymocyte apoptosis after irradiation [35], we measured the survival of thymocytes in vivo after radiation induced DNA damage. Under the conditions we used, cell survival depended largely on the genetic background. We registered the highest level of cell survival in the doubly hemizygous cells, where the rates were two fold greater in wild type cells and 1.5 fold greater than singly hemizygous cells. Since statistically, the number of damaged sites per cells should be the same for all genotypes, the differences in cell survival suggests that damage detection was less efficient in the double heterozygous cells and that more cells with DNA 


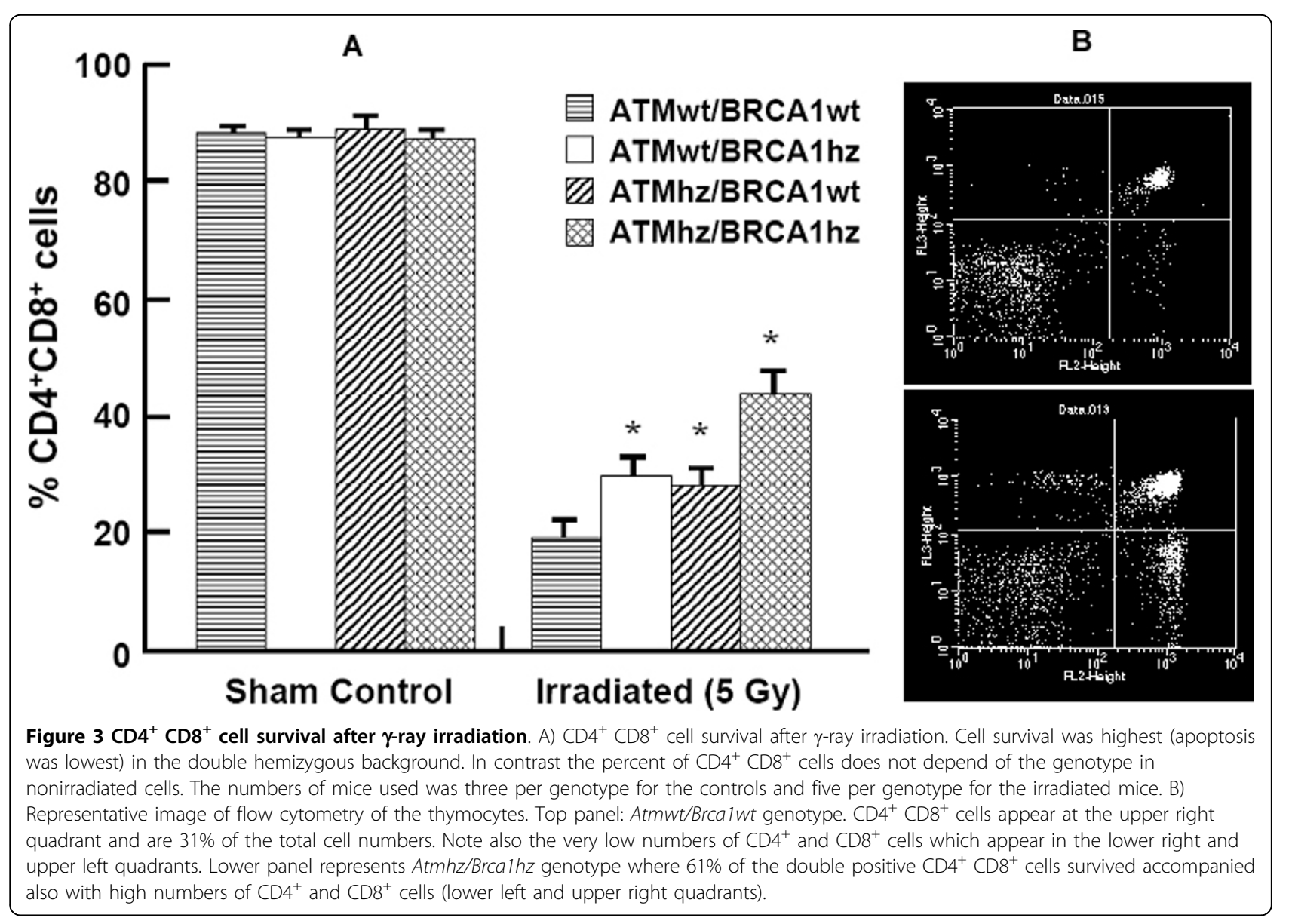

damage may accumulate in the thymuses of double heterozygous animals. Many if these cells will undergo apoptosis in subsequent division attempts but a very small fraction may survive increasing the probability of subsequent transformation.

The results from the estimation of the background DNA damage done by alkaline comet assay were somewhat unexpected for us. They clearly show that the background DNA damage is higher in the hemizygous genotypes. Since we didn't find difference in the background transformation frequency (and apoptosis, although apoptosis was measured in different cell type) between the heterozygous and wild type genotypes, we may conclude that the DNA damage detected by this method is not relevant to the background transformation frequency. It could be related though to the highest transformation levels in the heterozygous genotypes after irradiation where the combination of this damage and the one induced by radiation may result in higher degree genetic instability.

Considering the network of physical interactions between active factors in living cells may help to explain how it is that reduced levels of expression of a single protein may have such a large effect in the system of events which comprise the biology of the cell. Biological networks are capable of self assembly and disassembly. For example, many local networks may be assembled only when they are needed - for instance after DNA double-strand breaks are induced. The requirement for assembly in response to an event at an unknown point in a relatively large (on molecular scale) area, introduces spatial and quantitative limitations on the process. DNA double-strand breaks are a local event that may appear at any place in the nucleus. A local network has to be assembled at the points of DNA double-strand breaks in order to signal and initiate the repair. Proteins, potential members of the local networks, have to be in close proximity to the break or to be able to translocate quickly to the site. Several experiments confirmed that this is the case. Immunofluorescence analysis of cells after radiation induced DNA double-strand breaks show that many DNA repair proteins, like ATM, P53BP1, MRE11, Rad50 and NBS1, ATR, colocalize and form discrete foci on the sites of DNA damage [36,37]. In addition, migration of DNA repair proteins toward the site of DNA damage has been analyzed by FRAP. By 
measuring the diffusion coefficient of various repair proteins it has been shown that translocation and transient immobilization of RAD51, RAD52, RAD54 as well as the NER repair complex ERCC1-XPF and P53BP1 [38-40] occurs at DNA repair sites in mammalian cells. In the case of multiple DNA dsb, haploinsufficiency for ATM or BRCA1 may lead to incomplete assembly of the repair complex. As a result, some DNA dsb may not be detected or repaired and the cells will not fail to correctly undergo apoptosis. In this way, the failure of local networks could lead to the accrual of mutations in living cells.

\section{Conclusions}

In summary, we have shown that hemizygosity and combined hemizygosity for Atm and BRCA1 both constitute a prominent contribution to radiation induced cell transformation and apoptosis. While it has long been hypothesized that radiosensitivity in some individuals may well be the result of haploinsufficiency for low penetrance genes, little progress has been made in elucidating specific examples. We have now identified three genes with high penetrance and a low frequency of mutation that confer sensitivity to radiation induced effects, such as cancer. This is relevant given that the frequency of mutation of any individual sensitizing gene inducing heterozygosity among individuals in the general human population may be low and largely undetected. Compound heritable mutations inducing heterozygosity in more than one radio sensitizing gene could render a sub-population particularly radiosensitive. Since such heritable mutations can become concentrated in certain ethnic groups, elements of the human population may be especially vulnerable to radiation induced biological effects.

\section{Acknowledgements}

This study was supported in part by the Office of Science (BER), US Department of Energy, Grant No. DE-FG02-03ER63629, a grant from NASA No. NAG 9-1519 and the Century Program of the Chinese Academy of Sciences No. 0760140BRO.

\section{Author details \\ 'Institute of Modern Physics, Chinese Academy of Sciences, Lanzhou 730000, PR China. ${ }^{2}$ Center for Radiological Research, Columbia University Medical Center, New York, NY 10032, USA. ${ }^{3}$ Institute for Cancer Genetics, Columbia University Medical Center, New York, NY 10032, USA.}

\section{Authors' contributions \\ LBS and TL provided the mice, mating, genotyping, embryo cells isolation and culture. FS and LZ and GZ carried out the comet assay, transformation assays, apoptosis and micronuclei assay. EJH conceived the study and participated in its design and coordination. LBS and EJH drafted the manuscript. All authors read and approved the final manuscript.}

\section{Competing interests}

The authors declare that they have no competing interests.
Received: 16 November 2009

Accepted: 22 February 2010 Published: 22 February 2010

\section{References}

1. Bartek J, Lukas J, Bartkova J: DNA damage response as an anti-cancer barrier: damage threshold and the concept of 'conditional haploinsufficiency'. Cell Cycle 2007, 6:2344-2347.

2. Kastan MB, Bartek J: Cell-cycle checkpoints and cancer. Nature 2004, 432:316-323

3. Le Toriellec E, Despouy G, Pierron G, Gaye N, Joiner M, Bellanger D, Vincent-Salomon A, Stern MH: Haploinsufficiency of CDKN1B contributes to leukemogenesis in T-cell prolymphocytic leukemia. Blood 2008, $111 \cdot 2321-2328$

4. Santarosa M, Ashworth A: Haploinsufficiency for tumour suppressor genes: when you don't need to go all the way. Biochim Biophys Acta 2004, 1654:105-122.

5. Vladutiu GD: Heterozygosity: an expanding role in proteomics. Mol Genet Metab 2001, 74:51-63.

6. Yan H, Dobbie Z, Gruber SB, Markowitz S, Romans K, Giardiello FM, Kinzler KW, Vogelstein B: Small changes in expression affect predisposition to tumorigenesis. Nat Genet 2002, 30:25-26.

7. Cheo DL, Meira LB, Burns DK, Reis AM, Issac T, Friedberg EC: Ultraviolet B radiation-induced skin cancer in mice defective in the Xpc, Trp53, and Apex (HAP1) genes: genotype-specific effects on cancer predisposition and pathology of tumors. Cancer Res 2000, 60:1580-1584.

8. Kucherlapati M, Yang K, Kuraquchi M, Zhao J, Lia M, Heyer J, Kane MF, Fan K, Russell R, Brown AM, Kneitz B, Edelmann W, Kolodner RD, Lipkin M, Kucherlapati R: Haploinsufficiency of Flap endonuclease (Fen1) leads to rapid tumor progression. Proc Natl Acad Sci USA 2002, 99:9924-9929.

9. Umesako S, Fujisawa K, liga S, Mori N, Takahashi M, Hong DP, Song CW, Haga S, Imai S, Niwa O, Okumoto M: Atm heterozygous deficiency enhances development of mammary carcinomas in p53 heterozygous knockout mice. Breast Cancer Res 2005, 7:R164-170.

10. Smilenov LB, Lieberman HB, Mitchell SA, Baker RA, Hopkins KM, Hall EJ: Combined haploinsufficiency for ATM and RAD9 as a factor in cell transformation, apoptosis, and DNA lesion repair dynamics. Cancer Res 2005, 65:933-938.

11. Ahmed M, Rahman N: ATM and breast cancer susceptibility. Oncogene 2006, 25:5906-5911.

12. Athma P, Rappaport R, Swift M: Molecular genotyping shows that ataxiatelangiectasia heterozygotes are predisposed to breast cancer. Cancer Genet Cytogenet 1996, 92:130-134.

13. Renwick A, Thompson D, Seal S, Kelly P, Chagtai T, Ahmed M, North B, Jayatilake H, Barfoot R, Spanova K, McGuffog L, Evans DG, Eccles D, Easton DF, Stratton MR, Rahman N: ATM mutations that cause ataxiatelangiectasia are breast cancer susceptibility alleles. Nat Genet 2006, 38:873-875.

14. Gatti RA, Tward A, Concannon P: Cancer risk in ATM heterozygotes: a model of phenotypic and mechanistic differences between missense and truncating mutations. Mol Genet Metab 1999, 68:419-423.

15. Chenevix-Trench G, Spurdle AB, Gatei M, Kelly H, Marsh A, Chen X, Donn K, Cummings M, Nyholt D, Jenkins MA, Scott C, Pupo GM, Dork T, Bendix R, Kirk J, Tucker K, McCredie MR, Hopper JL, Sambrook J, Mann GJ, Khanna KK: Dominant negative ATM mutations in breast cancer families. J Natl Cancer Inst 2002, 94:205-215.

16. Thompson D, Duedal S, Kirner J, McGuffog L, Last J, Reiman A, Byrd P, Taylor M, Easton DF: Cancer risks and mortality in heterozygous ATM mutation carriers. J Natl Cancer Inst 2005, 97:813-822.

17. Becker-Catania SG, Chen G, Hwang MJ, Wang Z, Sun X, Sanal O, Bernatowska-Matuszkiewicz E, Chessa L, Lee EY, Gatti RA: Ataxiatelangiectasia: phenotype/genotype studies of ATM protein expression mutations, and radiosensitivity. Mol Genet Metab 2000, 70:122-133.

18. Khanna KK: Cancer risk and the ATM gene: a continuing debate. J Natl Cancer Inst 2000, 92:795-802.

19. Lahdesmaki A, Kimby E, Duke V, Foroni L, Hammarstrom L: ATM mutations in B-cell chronic lymphocytic leukemia. Haematologica 2004, 89:109-110.

20. Lavin MF: Ataxia-telangiectasia: from a rare disorder to a paradigm for cell signalling and cancer. Nat Rev Mol Cell Biol 2008, 9:759-769.

21. Shiloh Y: ATM and related protein kinases: safeguarding genome integrity. Nat Rev Cancer 2003, 3:155-168. 
22. Gatei M, Scott SP, Filippovitch I, Soronika N, Lavin MF, Weber B, Khanna KK: Role for ATM in DNA damage-induced phosphorylation of BRCA1. Cancer Res 2000, 60:3299-3304.

23. Greenberg RA: Recognition of DNA double strand breaks by the BRCA1 tumor suppressor network. Chromosoma 2008, 117:305-317.

24. Kim H, Chen J: New players in the BRCA1-mediated DNA damage responsive pathway. Mol Cells 2008, 25:457-461.

25. Fuller S, Liebens F, Carly B, Pastijn A, Rozenberg S: Breast cancer prevention in BRCA1/2 mutation carriers: a qualitative review. Breast J 2008, 14:603-604.

26. Elson A, Wang Y, Daugherty CJ, Morton CC, Zhou F, Campos-Torres J, Leder P: Pleiotropic defects in ataxia-telangiectasia protein-deficient mice. Proc Natl Acad Sci USA 1996, 93:13084-13089.

27. Ludwig T, Chapman DL, Papaioannou VE, Efstratiadis A: Targeted mutations of breast cancer susceptibility gene homologs in mice: lethal phenotypes of Brca1, Brca2, Brca1/Brca2, Brca1/p53, and Brca2/p53 nullizygous embryos. Genes Dev 1997, 11:1226-1241.

28. Smilenov LB, Brenner DJ, Hall EJ: Modest increased sensitivity to radiation oncogenesis in ATM heterozygous versus wild-type mammalian cells. Cancer Res 2001, 61:5710-5713.

29. Olive PL, Wlodek D, Durand RE, Banath JP: Factors influencing DNA migration from individual cells subjected to gel electrophoresis. Exp Cell Res 1992, 198:259-267.

30. Konca K, Lankoff A, Banasik A, Lisowska H, Kuszewski T, Gozdz S, Koza Z, Wojcik A: A cross-platform public domain PC image-analysis program for the comet assay. Mutat Res 2003, 534:15-20.

31. Krug U, Ganser A, Koeffler HP: Tumor suppressor genes in normal and malignant hematopoiesis. Oncogene 2002, 21:3475-3495.

32. Payne SR, Kemp CJ: Tumor suppressor genetics. Carcinogenesis 2005, 26:2031-2045

33. Smilenov LB: Tumor development: haploinsufficiency and local network assembly. Cancer Lett 2006, 240:17-28

34. Futreal PA, Coin L, Marshall M, Down T, Hubbard T, Wooster R, Rahman N, Stratton MR: A census of human cancer genes. Nat Rev Cancer 2004 4:177-183.

35. Xu Y, Ashley T, Brainerd EE, Bronson RT, Meyn MS, Baltimore D: Targeted disruption of ATM leads to growth retardation, chromosomal fragmentation during meiosis, immune defects, and thymic lymphoma. Genes Dev 1996, 10:2411-2422.

36. Falck J, Coates J, Jackson SP: Conserved modes of recruitment of ATM ATR and DNA-PKcs to sites of DNA damage. Nature 2005, 434:605-611.

37. Rouse J, Jackson SP: Interfaces between the detection, signaling, and repair of DNA damage. Science 2002, 297:547-551.

38. Asaithamby A, Chen DJ: Cellular responses to DNA double-strand breaks after low-dose \{gamma\}-irradiation. Nucleic Acids Res 2009.

39. Essers J, Houtsmuller AB, van Veelen L, Paulusma C, Nigg AL, Pastink A, Vermeulen W, Hoeijmakers JH, Kanaar R: Nuclear dynamics of RAD52 group homologous recombination proteins in response to DNA damage. EMBO J 2002, 21:2030-2037.

40. Houtsmuller $A B$, Rademakers $S$, Nigg AL, Hoogstraten D, Hoeijmakers $J H_{\text {, }}$ Vermeulen W: Action of DNA repair endonuclease ERCC1/XPF in living cells. Science 1999, 284:958-961.

doi:10.1186/1748-717X-5-15

Cite this article as: Su et al.: Hemizygosity for Atm and Brca1 influence the balance between cell transformation and apoptosis. Radiation Oncology 2010 5:15.

\section{Submit your next manuscript to BioMed Central and take full advantage of:}

- Convenient online submission

- Thorough peer review

- No space constraints or color figure charges

- Immediate publication on acceptance

- Inclusion in PubMed, CAS, Scopus and Google Scholar

- Research which is freely available for redistribution

Submit your manuscript at www.biomedcentral.com/submit
Biomed Central 